\title{
Towards a Research Agenda for Gameful Creativity
}

Sarah-Kristin Thiel

Department of Computer

Science, Aarhus University

Aarhus, Denmark

thiel@cs.au.dk

Christian Remy

Centre for Digital Creativity,

Aarhus University

Aarhus, Denmark

remy@cc.au.dk

Licinio Roque

University of Coimbra

Coimbra, Portugal

lir@dei.uc.pt

Rita Orji

Faculty of Computer Science,

Dalhousie University

Halifax, NS, B3H 4R2, Canada

rita.orji@dal.ca

Permission to make digital or hard copies of part or all of this work for personal or

classroom use is granted without fee provided that copies are not made or distributed for profit or commercial advantage and that copies bear this notice and the full citation on the fist page. Copyrights for and party conponents or his wort

DIS'19 Companion, June 23-28, 2019, San Diego, CA, USA

() 2019 Copyright is held by the author(s)
Peter Dalsgaard

Centre for Digital Creativity,

(arhus University

Aarhus, Denmark

dalsgaard@cavi.au.dk

Celine Latulipe

University of North Carolina

Charlotte, North Carolina, US

clatulip@uncc.edu

Sayan Sarcar

University of Tsukuba

Tsukuba, Japan sayans@slis.tsukuba.ac.jp

https://doi.org/10.1145/3301019.3320003

\begin{abstract}
We propose a one-day workshop that focuses on the intersection of gamefulness and creativity. The objective of this workshop is to bring together both researchers and practitioners interested in this field to discuss a research agenda that will explore the relationship between game-related aspects (e.g. game play, game genres) and creative thinking. Embracing the interdisciplinarity of creativity, we invite researchers from a variety of fields including but not limited to games, gamification, playfulness and creativity research. In a highly interactive format, we aim to consolidate previous work, identify relevant areas for future research, and discuss methods to assess the effectiveness of gamefulness on individuals' creative potential. As outcomes of the workshop we hope to set a research agenda and establish a vibrant community around the domain of gamefulness and creativity.
\end{abstract}

\section{Author Keywords}

Creativity; gamefulness; games; gamification; creative processes; creative tools; divergent thinking.

\section{CCS Concepts}

-Human-centered computing $\rightarrow$ Human computer interaction (HCl); User studies; 


\section{Background}

In light of social and economical structures becoming more global and essentially dynamic, creative thinking and creativity as a trait in general are becoming ever more valuable [11]. For ideas (e.g., for products or services) to be successful nowadays requires the ability to come up with solutions that are competitive in a rapidly changing environment [9]. Relying on innovation, various industries have identified creativity as key driver for their (industrial) development [12, 2]. This increasing demand for creative individuals calls for infrastructures and measures to activate, promote and harness creative thinking. As a consequence from the statement from the UNESCO that creativity can be taught, several educational approaches have been put forward [19]. We argue that such creativity courses do not necessarily have to a) take place in educational settings and b) be all serious. To that end, we argue that gamefulness could be an approach to activate, explore, and promote creativity.

We employ the term "gamefulness" to reflect both gamification approaches and games. Oriented on the matrix of entertainment design [4], we distinguish between gamification, games and play as potential strategies to enhance creative thinking. To that end, we see play as free exploration, games as rule-driven activity where a goal is pursued, and gamification as utilization of a selection of game elements to direct behavior $[1,16]$. There are no sharp lines between those concepts as they are usually subjective. Both axes of the matrix (play-game, whole-part) should hence be seen as continuum.

A starting point to the intersection of gamefulness and creativity might be the early 1900 s when test-like conditions where compared to play-like conditions in the context of creativity tests [7]. With the attention now increasingly on the effect of video games on creativity $[8,20]$, the notion of "play-like conditions" has shifted to a more entertainmentbased approach to promote creative thinking.

Research on the relationship between video game play and creativity warrants further exploration; not only because existing studies seem to show contradictory results $[6,10]$ but also since there is a lack in studies investigating differences in the effect of game types (e.g. console vs. mobile) and genres (e.g. puzzle vs. simulation) as well as the role of collaboration. Furthermore, in the context of creativity game play and play have been discussed as one entity, but little attention has been on the exact composition and structure (i.e. game-related elements; cf. [11]). With this workshop, we hope to establish a research agenda for implementing gamefulness to enhance creative thinking that is grounded in previous work.

Moreover, recent work suggests that the impact of game mechanics on motivation is closely linked to users' game profiles [15]. Not everyone looks for the same experiences in games; for instance, some prefer working in teams over competing against each other [5, 15]. Reflecting on this, various scholars have introduced conceptual models to describe different aptitudes for experiences in games (e.g., Bartle's or Marczweski's player types [3, 13]). Seeing that creativity is influenced not only by motivation but also individual needs such as autonomy ([17]), we argue that tai-

loring for individual preferences when adding gamefulness to foster creativity might increase the effectiveness. To that end, also personality traits have been shown to affect both preferences for games/game-play and creativity [18, 14].

In the proposed workshop, we hence want to explore how recent insights regarding personalisation strategies can be applied to enhance gameful creative processes.

At this stage of the development of a research agenda, we are not focusing on evaluating any of the proposed meth- 
ods or discussed approaches to spark creative potentia through gameful approaches. Similarly, while we understand creativity as an ability to produce something new and meaningful, we are not set on one definition of creativity. To that end, we postpone the debate on whether and how creativity can be measured to a later point in time; potentially as a continuation of the proposed workshop.

\section{Workshop Goals and Themes}

The overall objective of this workshop is to bring researchers interested or experienced in the intersection of creativity and gamefulness together to jointly develop a research agenda focusing on the question of how gamefulness can be used to foster creative potential. This should not result in a once-only activity, but create a community that brings life to a jointly developed research agenda through activities such as collaborating on user studies and publications.

By keeping the call for participants open to researchers from various backgrounds, we aim to gain a broader overview of relevant aspects and existing work as well as encourage interdisciplinarity in the field of gameful creativity. One central aspect of the workshop's activities will be a gameful ideation exercise, connecting all the different backgrounds of workshop attendees together. Building on the principals of card-based innovation games, this gameful ideation exercise will allow us to illustrate the potential of combining gamefulness and creativity.

\section{Acknowledgements}

This project has received funding from the European Research Council (ERC) under the European Union's Horizon 2020 research and innovation programme (\# 740548).

\section{REFERENCES}

1. Ana Paula Varela Afonso and Licinio Roque. 2015. Reflections on playfulness, imagination and creativity, their relations and open questions. In Information Systems and Technologies (CISTI), 2015 10th Iberian Conference on. IEEE, 1-5.

2. Teresa M Amabile. 1997. Motivating creativity in organizations: On doing what you love and loving what you do. California management review 40, 1 (1997), 39-58.

3. Richard Bartle. 1996. Hearts, Clubs Diamonds, Spades: Players who suit MUDs. Journal of MUD research 1, 1 (1996), 19.

4. Sebastian Deterding, Dan Dixon, Rilla Khaled, and Lennart Nacke. 2011. From Game Design Elements to Gamefulness: Defining Gamification. In Proceedings of the 15th International Academic MindTrek Conference on Envisioning Future Media Environments - MindTrek '11. 9-11. DOI :

http://dx.doi.org/10.1145/2181037.2181040

5. Alexandra Eveleigh, Charlene Jennett, Stuart Lynn, and Anna L. Cox. 2013. "I want to be a Captain! I want to be a Captain!": Gamification in the Old Weather Citizen Science Project. In Proceedings of the First International Conference on Gameful Design, Research, and Applications - Gamification '13. 79-82. DOI : http: //dx.doi .org/10.1145/2583008. 2583019

6. Karla R Hamlen. 2009. Relationships between Computer and Video Game Play and Creativity among upper elementary School Students. Jorunal of Educational Computing Research 40, 1 (2009), 1-21. DOI : http://dx.doi.org/10.2190/EC.40.1.a 
7. John A Hattie. 1977. Conditions for Administering Creativity Tests. Psychological Bulletin 84, 6 (1977), 1249-1260.

8. Elizabeth Hutton and S Shyam Sundar. 2010. Can Video Games Enhance Creativity? Effects of Emotion Generated by Dance Dance Revolution. Creativity Research Journal 22, 3 (2010), 294-303. DOI : http://dx.doi.org/10.1080/10400419.2010.503540

9. Scott G Isaksen, Kenneth J Lauer, Goran Ekvall, Alexander Britz, S G Isaksen, K J Lauer, G Ekvall, A Britz, Fainstitute Stockholm, and Sweden Alexander Britz. 2001. Perceptions of the Best and Worst Climates for Creativity: Preliminary Validation Evidence for the Situational Outlook Questionnaire. Creativity Research Journal 13, 2 (2001), 1040-419.

10. Linda A Jackson, Edward A Witt, Alexander Ivan Games, Hiram E Fitzgerald, Alexander Von Eye, and Yong Zhao. 2012. Information technology use and creativity: Findings from the Children and Technology Project. Computers in Human Behavior 28, 2 (2012), 370-376. DOI :

http://dx.doi.org/10.1016/j.chb.2011.10.006

11. Marius Kalinauskas. 2014. Gamification in Fostering Creativity. Social Technologies 4, 1 (2014), 62-75. DOI : http://dx.doi .org/10.13165/ST-14-4-1-05

12. Ximena López and Carlo Fabricatore. 2012. Fostering Students' Creativity Through Video Game Development. IEEE 12th International Conference on Advanced Learning Technologies (ICALT) (2012), 340-341. http://eprints. worc. ac.uk/1944/1/Lopez

13. Andrzej Marczewski. 2015. User Types. In Even Ninja Monkeys Like to Play: Gamification, Game Thinking and Motivational Design. 65-80.
14. Rita Orji, Chrysanne Di Marco, and Lennart E Nacke. 2017a. Towards Personality-driven Persuasive Health Games and Gamified Systems. In Proceedings of the 2017 CHI Conference on Human Factors in Computing Systems. ACM, 1015-1027. DOI : http://dx.doi.org/10.1145/3025453.30255

15. Rita Orji, Regan L Mandryk, and Julita Vassileva. 2017b. Improving the Efficacy of Games for Change Using Personalization Models. ACM Transaction of Computer-Human Interaction 24, 22 (2017). DOI : http://dx.doi. org/10.1145/3119929

16. Luis Lucas Pereira and Licínio Roque. 2012. Towards a game experience design model centered on participation. In CHI'12 Extended Abstracts on Human Factors in Computing Systems. ACM, 2327-2332.

17. Kennon M. Sheldon. 1995. Creativity and SelfDetermination in Personality. Creativity Research Journal 8, 1 (1995), 25-36.

18. Paulj Silvia, Beatep Winterstein, Johnt Willse, Christopherm Barona, Joshuat Cram, Karli Hess, Jennal Martinez, and Andcrystala Richard. 2008. Assessing Creativity with Divergent Thinking Tasks: Exploring the Reliability and Validity of new Subjective Scoring Methods. Psychology of Aesthetics, Creativity, and the Arts 2, 2 (2008), 68-85.

19. Fangqi Xu, Ginny McDonnel, and William R. Nash. 2005. A Survey of Creativity Courses at Universities in Principal Countries. The Journal of Creative Behavior 39, 2 (2005), 75-88.

20. Chloe Shu-Hua Yeh. 2015. Exploring the effects of videogame play on creativity performance and emotional responses. Computers in Human Behavior 53 (dec 2015), 396-407. DOI : http://dx.doi.org/10.1016/J.CHB.2015.07.024 